\title{
Hypothyroidism-A Question towards Quality and Patient Centricity
}

\author{
Hina Rehman ${ }^{*}$, Syed Junaid Rehan², Humera Ishaq2 ${ }^{2}$, Sadia Shakeel1', Faraz Hashmi3, \\ Safila Naveed 1 \\ ${ }^{1}$ Faculty of Pharmacy, Jinnah University for Women, Karachi, Pakistan \\ ${ }^{2}$ Faculty of Pharmacy, Hamdard University, Karachi, Pakistan \\ ${ }^{3}$ Jinnah Sindh Medical University, Karachi, Pakistan \\ Email: *drhinarehman@hotmail.com
}

Received 24 January 2015; accepted 11 February 2015; published 26 February 2015

Copyright (C) 2015 by authors and Scientific Research Publishing Inc.

This work is licensed under the Creative Commons Attribution International License (CC BY). http://creativecommons.org/licenses/by/4.0/

(c) (i) Open Access

\section{Abstract}

The metabolic and endocrine disorders are either increasing across the globe or may have been observed with more focus in recent years. It is not uncommon now to find out neither patients of endocrine and metabolic disorders nor a physician of the associated diseases. There were 42 million people who had thyroid disorders including hypothyroidism according to the survey of endocrine society of India. Hypothyroidism is said when less activity of thyroid glands is observed than the normal. So, to evaluate the quality standard, empowerment and patient centricity in Pakistan with present prevalence of hypothyroidism in different age groups, gender along with the prescribed medication against pre-diagnosed disease and associated co-morbidities, the study is designed with a questionnaire development including both qualitative and quantitative variables. Study was conducted on various OPD's, profit and not for profit secondary and tertiary care hospitals and consultant clinics during July 2013 to Jan 2014 and it was given consideration to include people from all areas of life with minimization of any unforeseen biasness and comprehensive data. After full filling the inclusion criteria, 102 patients were selected as study participants. After completion and reviewing the questionnaire, data were analyzed by 21.00 SPSS version. Chi square/ fisher test, spearmen's rank correlation were applied for categorical quantitative variable. Paired $t$ test before and after were applied for qualitative variable. Highly significant reliability of items in the questionnaire was found along with inter item correlation $(P<0.05)$. Out of 102 patients of the study, 80 patients fell into the inclusion criteria, while 22 were excluded. A total of 80 patients were registered in the incorporate duration. Among the total samples $36(42.9 \%)$ were males and $44(52.4 \%)$ were females. Mean age males and females included in the study were $34.89 \pm 17.73$ and $33.36 \pm 13.73$ years respectively. The systolic and diastolic blood pressure $(120 / 80 \mathrm{mg} \mathrm{Hg})$ was observed in 18 (40.9\%) females' and $13(36.1 \%)$ males' patients. Quality, patient centricity and empowerment were the poor areas which need additional consultations and counseling for crutches free environment.

\footnotetext{
"Corresponding author.
} 


\section{Keywords}

\section{Hypothyroidism, Quality, Patient Centricity, Empowerment}

\section{Introduction}

Hypothyroidism is an endocrine disorder. A number of factors have influence on the development of hypothyroidism such as: gender [1], genetic predisposition [2], and smoking habit [3]. Hypothyroidism brings most frequent changes in cardiac hemodynamics like the increase of systemic vascular resistance, decrease of cardiac preload and reduction of diastolic and systolic function [4]. The symptoms which are associated with hypothyroidism are cardiac dysfunction, dyspnea on effort and reduced exercise tolerance [5] [6], and overt cardiovascular diseases [7]. Hypothyroidism also increases the frequency of a variety of other conditions, such as rheumatic diseases, lung diseases [8], and diabetes mellitus [9]-[11]. Congenital hypothyroidism is thyroid hormone deficiency present at birth. It is mostly caused by a problem in thyroid gland development called dysgenesis or a disorder of thyroid hormone biosynthesis called dyshormonogenesis. Such disorders result in primary hypothyroidism (PH). A deficiency of thyroid stimulating hormone (TSH) at birth causes secondary or central hypothyroidism. Congenital hypothyroidism is classified into permanent and transient congenital hypothyroidism (CH). Permanent $\mathrm{CH}$ is a persistent deficiency of thyroid hormone and requires life-long treatment. Transient $\mathrm{CH}$ is discovered at birth and is a temporary deficiency of thyroid hormone, but the condition get normalize to normal thyroid hormone production. In the first few months or years of life recovery, euthyroidism typically occurs. Permanent $\mathrm{CH}$ can be further divided into permanent primary and secondary (or central) $\mathrm{CH}$; transient primary $\mathrm{CH}$ has also been reported. Some forms of $\mathrm{CH}$ are associated with defects in other organ systems; these are classified as syndromic hypothyroidism [12].

Amongst various segments, we have endocrinologists with their staff including paramedics, dieticians, psychologist, physiotherapist, etc., managing their patients without the concept of awareness and empowerment [13] [14]. Then there are other endocrinologists who have educated the pool of patients and are helping to build a successful addition towards quality care and empowerment [15].

Empowerment means we treat every patient on individual basis (patient centricity), listen for their concern, educate and provide them with the comprehensive knowledge about the disease and situation, invite and encourage them to be the part of decision making process according to the capability. It is a demand of today that we ensure admittance for patients to ongoing education after evaluation the holistic nature of need and self-management support from all relevant discipline [16].

This study was designed and conducted keeping specifically related focus on patient empowerment, patient quality and centricity precisely in case of hypothyroidism, the prevalence rate of hypothyroidism in our society were $(4.1 \%-4.5 \%)$. Another aspect of the study design was to find out the awareness of related comorbid conditions with hypothyroidism, as it was felt that this was the area which needed to be explored to have better understanding for the patients care.

\section{Materials and Methods}

In this study, we highlighted the prevalence of hypothyroidism with different ages, genders, caste, occupation, knowledge, current symptoms \& complain history of past and current medication, drug interactions, diagnostic criteria, knowledge related to quality of life and awareness, responsiveness about patient centricity and empowerments etc. in our society.

\subsection{Study Design}

It was an analytical cross sectional study carried out in the span of June 2013 to Jan 2014. Total 102 patients were selected, but after screening through inclusion criteria 80 patients were enrolled.

The patients who were able to give the consent came under inclusion criteria while those who had some reservation related to consent or participating in any other study were excluded due to decision biasness.

Sampling techniques of the study were nonsystematic randomized. Questionnaires were distributed in differ- 
ent charitable and non-charitable secondary and tertiary care hospitals and consultation clinics.

\subsection{Tool Development}

The basic tool selected to conduct the study was questionnaire which was developed through the review of literature and researches available in this area and also added the aspects of society fatal and mournful event.

The questionnaire was designed in a way that it comprises of two portions. First portion consists on demographics associated 5 questions. The second portion had 28 questions which were further sub divided into 5 areas. There were 4 questions related to the history, sign and symptoms, 9 questions were related to the medications, 3 were related to diagnosis, 2 were related to the drug manufacturing vicinity issues and 7 questions related to the quality, patient centricity and empowerment. The questionnaire was then evaluated \& reviewed by the HCPs for content validity and further verified and reviewed by university's IRB.

\subsection{Data Collection}

Data collected from different hospitals profit and nonprofit both .Subjects were randomly chosen from different vicinity of the city. Purely nonsystematic randomized collection of the data minimizes the biasness and conflict of interest.

Patients seem reluctant and ignorant when the counseling related to empowerment and patient centricity was asked.

\subsection{Limitations}

There were no limitations but the patient S not responding to the questions and the diagnosed condition seriously was the actual constraint. The concept of "thinking me without me" were completely tried to deliver the patients with all-time obliges and limitations. It tried to convey the patients that you are the person for your decisions, you are the person who can empower yourself.

\subsection{Statistical Analysis}

Chi square/fisher test, spearmen's rank correlation were applied for categorical quantitative variable. Paired $\mathrm{t}$ test before and after were applied for qualitative variable. Highly significant reliability of items in the questionnaire was found along with inter item correlation $(\mathrm{P}<0.05)$ were found significant.

\section{Discussion}

Based on the available data of patients, up to the age of $25 \mathrm{yrs}$, 31.3\% of total populations (33.3\% male \& 29.5\% female) were suffering from hypothyroidism. Between 25 to 35 years old, 31.3\% suffered from hypothyroidism with $36.1 \%$ male (34.89 \pm 17.73 Mean, SD) and 27.3\% women (33.36 \pm 13.73 Mean, SD) respectively. At the age group of 36 to 45 years, $16.3 \%$ of the population suffered from the disease in which $5.6 \%$ of male and $14 \%$ of female having the disease and P value was $<0.034$ as seen in Table 1 . For the group of 46 to 55 years, $10 \%$ of population ( $6 \%$ male $\& 14 \%$ female) having hypothyroidism. Over 55 years, $11 \%$ of the population having the disease with $19 \%$ of men $\& 5 \%$ of women respectively.

$26 \%$ of population ( $17 \%$ male \& $34 \%$ female) having blood pressure in the range of $50 / 100$. About $39 \%$ of the patients have blood pressure in the range of $80 / 120$ ( $36 \%$ male $\& 41 \%$ female respectively). As per Table 1 , about $35 \%$ subjects ( $47 \%$ men $\& 25 \%$ women) having blood pressure in the range of 90/150 $(\mathrm{P}<0.05)$.

$58.8 \%$ of subjects suffered from hypothyroidism belonged to rural areas while the rest belonged to urban areas as per Table 1. Further $47 \%$ of men belonging to rural areas \& $53 \%$ belonging to urban areas suffered from the disease while $68 \%$ of women belonging to rural areas and $32 \%$ belonging to urban areas suffered from hypothyroidism $(\mathrm{P}<0.06)$. Subject knowledge about its diseases were found to be $41.3 \%$ and $58.8 \%$ of the subjects were unaware about their diseases $(\mathrm{P}=0.08)$.

People belongs to various areas of life were suffering from the disease. Majority of the population in which $29 \%$ of housewives suffered from the disease, while $18 \%$ teachers, $14 \%$ factory worker, $9 \%$ engineers, $8 \%$ sales and marketing personnel, $5 \%$ drivers, $4 \%$ pharmacist and $15 \%$ belonging to different professions were observed in the study. $55 \%$ of hypothyroidism patients ( $64 \%$ men, $48 \%$ women) have past medical history. On comparison 
Table 1. Patients conditions, complains, symptoms and medications.

\begin{tabular}{|c|c|c|c|c|c|}
\hline Questions & & Total & Male & Female & $P$ value \\
\hline \multirow{5}{*}{ Subject age } & Up to $25 y r s$ & 25 (31.3\%) & 12 (33.3\%) & 13 (29.5\%) & \multirow{5}{*}{$0.034^{*}$} \\
\hline & $26-35 y r s$ & $25(31.3 \%)$ & $13(36.1 \%)$ & $12(27.3 \%)$ & \\
\hline & $36-45 y r s$ & $13(16.3 \%)$ & $2(5.6 \%)$ & $11(25 \%)$ & \\
\hline & $46-55 y r s$ & $8(10 \%)$ & $2(5.6 \%)$ & $6(13.6 \%)$ & \\
\hline & Above 55 yrs & 9 (11.3\%) & 7 (19.4\%) & $2(4.5 \%)$ & \\
\hline \multirow{3}{*}{ Subject blood pressure } & $110 / 50 \mathrm{mmHg}$ & $21(26.3 \%)$ & $6(16.7 \%)$ & $15(34.1 \%)$ & \multirow{3}{*}{$0.05^{*}$} \\
\hline & 120/80mmHg & $31(38.8 \%)$ & $13(36.1 \%)$ & $18(40.9 \%)$ & \\
\hline & 150/90mmHg & $28(35 \%)$ & $17(47.2 \%)$ & $11(25 \%)$ & \\
\hline \multirow{2}{*}{ Subject area/district } & Urban & $33(41.3 \%)$ & $19(52.8 \%)$ & $14(31.8 \%)$ & \multirow{2}{*}{0.06} \\
\hline & Rural & $47(58.8 \%)$ & $17(47.2 \%)$ & $30(68.2 \%)$ & \\
\hline \multirow{2}{*}{ Subject knowledge about its diseases } & Yes & $33(41.3 \%)$ & $11(30.6 \%)$ & $22(50 \%)$ & \multirow{2}{*}{0.08} \\
\hline & No & $47(58.8 \%)$ & 25 (69.4\%) & $22(50 \%)$ & \\
\hline \multirow{8}{*}{ Occupation of hypothyroidism patients } & Engineer & $9 \%$ & $17 \%$ & $2 \%$ & \multirow{8}{*}{$0.000\left(^{*}, \mathrm{a}\right)$} \\
\hline & Sales and marketing & $8 \%$ & $6 \%$ & $\begin{array}{c}9 \\
9 \%\end{array}$ & \\
\hline & Pharmacist & $4 \%$ & $0 \%$ & $7 \%$ & \\
\hline & Teacher & $18 \%$ & $22 \%$ & $14 \%$ & \\
\hline & Factory worker & $14 \%$ & $28 \%$ & $2 \%$ & \\
\hline & Driver & $5 \%$ & $8 \%$ & $2 \%$ & \\
\hline & House wife & $29 \%$ & $0 \%$ & $52 \%$ & \\
\hline & Others & $15 \%$ & $19 \%$ & $11 \%$ & \\
\hline $\begin{array}{l}\text { Is hypothyroidism and calcium deficient } \\
\text { patients wearing hijab or burka? }\end{array}$ & $\begin{array}{l}\text { Patients wearing } \\
\text { hijab or burka }\end{array}$ & $29 \%$ & $0 \%$ & $52 \%$ & $0.000\left(^{*}\right)$ \\
\hline \multirow{5}{*}{ History related to hypothyroidism } & 1 - 2 year & $37(46.3 \%)$ & $17(47.2 \%)$ & $20(45.5 \%)$ & \multirow{5}{*}{$0.724(\mathrm{a}, \mathrm{c})$} \\
\hline & 3 - 4 year & $30(37.5 \%)$ & $15(41.7 \%)$ & $15(34.1 \%)$ & \\
\hline & $5-6$ year & $10(12.5 \%)$ & $3(8.3 \%)$ & 7 (15.9\%) & \\
\hline & 7 - 8 year & $1(1.3 \%)$ & $0(0 \%)$ & $1(2.3 \%)$ & \\
\hline & 9 - 10 year & $2(2.5 \%)$ & $1(2.8 \%)$ & $1(2.3 \%)$ & \\
\hline \multirow{2}{*}{ Current medical sign and symptoms } & Yes & $44(55 \%)$ & $23(63.9 \%)$ & $21(47.7 \%)$ & \multirow{2}{*}{0.15} \\
\hline & No & $36(45 \%)$ & $13(36.1 \%)$ & $23(52.3 \%)$ & \\
\hline \multirow{2}{*}{ Subject other diagnosed diseases } & Yes & $18(22.5 \%)$ & $8(22.2 \%)$ & $10(22.7 \%)$ & \multirow{2}{*}{0.96} \\
\hline & No & $62(77.5 \%)$ & $28(77.8 \%)$ & $34(77.3 \%)$ & \\
\hline \multirow{4}{*}{$\begin{array}{l}\text { Importance related to calcium } \\
\text { supplement in your diet }\end{array}$} & Not aware & $43(53.8 \%)$ & $18(50 \%)$ & $25(56.8 \%)$ & \multirow{4}{*}{$0.038\left(^{*}, a\right)$} \\
\hline & Aware and apply & $4(5 \%)$ & $3(8.3 \%)$ & $1(2.3 \%)$ & \\
\hline & It’s not needed & $16(20 \%)$ & $11(30.6 \%)$ & $5(11.4 \%)$ & \\
\hline & Others & $17(21.3 \%)$ & $4(11.1 \%)$ & $13(29.5 \%)$ & \\
\hline \multirow{2}{*}{ Usual milk intake in your daily diet } & Yes & $55(68.8 \%)$ & $22(61.1 \%)$ & $33(75 \%)$ & \multirow{2}{*}{0.18} \\
\hline & No & $25(31.3 \%)$ & $14(38.9 \%)$ & $11(25 \%)$ & \\
\hline \multirow{5}{*}{ If yes, how often? } & Rarely & $42(52.5 \%)$ & $20(55.6 \%)$ & $22(50 \%)$ & \multirow{5}{*}{$0.005^{*}(\mathrm{a})$} \\
\hline & Once in a week & $20(25 \%)$ & $5(13.9 \%)$ & 15 (34.1\%) & \\
\hline & Once in a month & $4(5 \%)$ & $4(11.1 \%)$ & $0(0 \%)$ & \\
\hline & Daily & $10(12.5 \%)$ & $5(13.9 \%)$ & $5(11.4 \%)$ & \\
\hline & Twice a day & $4(5 \%)$ & $2(5.6 \%)$ & $2(4.5 \%)$ & \\
\hline \multirow{2}{*}{$\begin{array}{l}\text { Taking nutritional product } \\
\text { other than calcium }\end{array}$} & Yes & $30(37.5 \%)$ & $16(44.4 \%)$ & $14(31.8 \%)$ & \multirow{2}{*}{0.25} \\
\hline & No & $50(62.5 \%)$ & $20(55.6 \%)$ & $30(68.2 \%)$ & \\
\hline
\end{tabular}




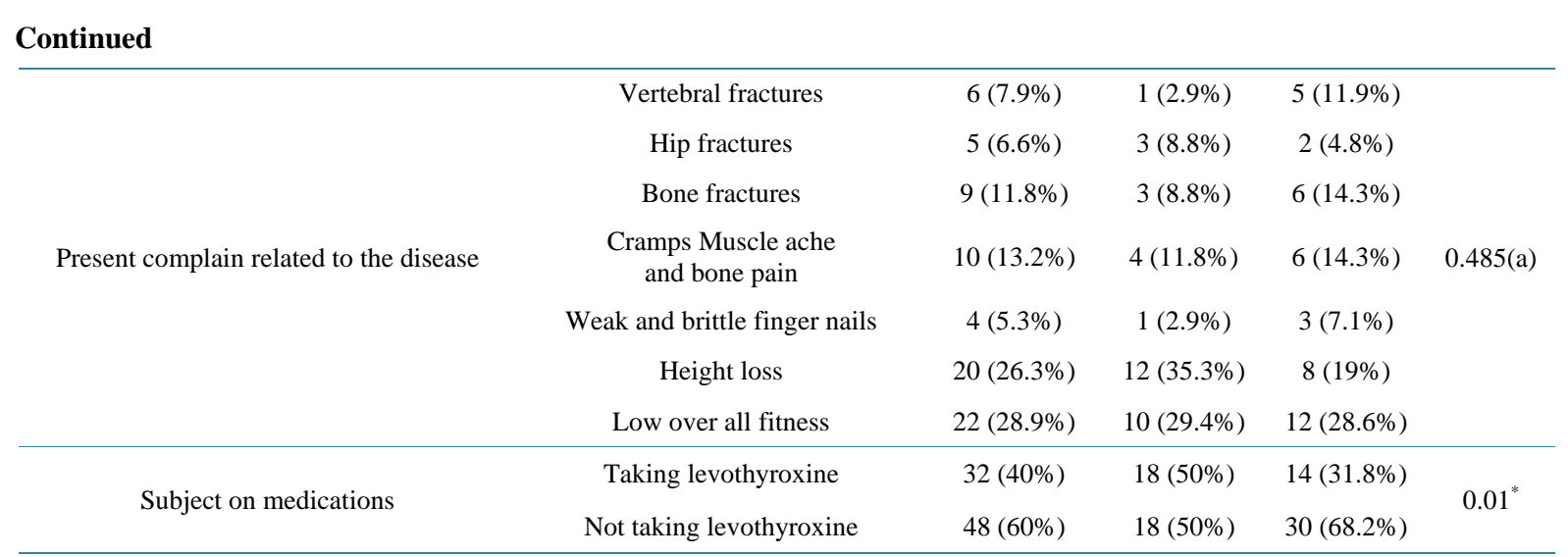

with the gender $(\chi 2$ value $=39.2 ; \mathrm{P}=0.000$; highly significant $)$ as shown in Table 1 .

As shown in Table 1, 52\% of hypothyroid women we studied wore hijab. Corelation between the 2 needs is to be studied. $23 \%$ of patients also suffered from other diseases. Relationship between the hijab and calcium deficiency were found to be $\mathrm{P}=0.000$.

$41 \%$ patients (31\% male \& 50\% female) had knowledge of disease. $69 \%$ of population ( $61 \%$ male, $75 \%$ female) suffering from hypothyroidism were taking milk on regular basis in their diet, as per Table $1,38 \%$ of patients (44\% male, 32\% female) were also taking other nutritional supplement products containing calcium. $(\chi 2=$ $7.2 ; \mathrm{P}=0.007)$

$40 \%$ of patients (50\% men \& 32\% women) took levothyroxine. Surprisingly about $97 \%$ of the patient was using national brands of the drug while only few i.e. just $3 \%$ depended on international brands of the drug as per Table 1. The comparison between the local and international users were found to be highly significant i.e. $(\mathrm{P}=$ 0.01) as shown in Table 2. Peripheral edema were found to be significantly high in the patients who were taking local manufactured levothyroxine with no other supplement, Friedman's chi-square test were found to be significantly high ( $\mathrm{f}=16.730 ; \mathrm{P}=0.000)$ as shown in Table 1 .

Drug interaction between levothyroxine and calcium was found to be very high in the study population. Most of the participants were not taking any medication with the main drug of hypothyroidism and did not use any other supplement $\mathrm{P}=0.34$ as per Table 1 , while in young patients the ratio were found to be significant $\mathrm{P}=0.03$. While normal patients were using local manufacturing brand rather than international $(P=0.001)$ as shown in Table 4 which were leading to multiple other associated problem like muscle cramps, anxiety, etc.

When the patients were asked about any complain they have, the top five issues reported that were found are depression, fatigue, swelling in lower extremities and weight gain respectively and comprising over $60 \%$ of the reported issues. The other complaints were about libido, hair loss, infertility, recurrent abortion in females and cold or hot intolerance as per Table 3.

$65 \%$ of the patients (67\% male and $64 \%$ female) were having muscles cramps and pain in their bones. $60 \%$ of the patients were facing depression and anxiety; women were largely fall in this group (56\% male and $64 \%$ female) as per Table $3.54 \%$ of the patients (53\% male and $54 \%$ female) were complaining weakness and fatigue. About $48 \%$ of the patients ( $47 \%$ male and $48 \%$ female) were having edema in their lower extremities. Behavioral changes and mood swing was also common in $40 \%$ of the patients (33\% male, $45 \%$ female). The overall fitness of about $38 \%$ of the patients (31\% male and $43 \%$ female) was reduced. About $27 \%$ of the patients (33\% male and $39 \%$ female) were complaining cracking and creaking of their skin. About $27 \%$ of female were having their menstrual cycle disturbed as shown in Figure 1. About 20\% of the patients (19\% male and 20\% female) were suffering from vertigo. Some of the patients about $18 \%$ (19\% male, $16 \%$ female) were having back pain. $16 \%$ of the patients (19\% male and $14 \%$ female) were having grating sensation. About $14 \%$ of the male as well as female were associated with heart diseases along with hypothyroidism. The finger nails of $13 \%$ of the patients ( $8 \%$ male and $16 \%$ female) were weak and brittle. About $9 \%$ of the patients ( $8 \%$ male and $9 \%$ female) were having bone fracture. $5 \%$ of the patients ( $8 \%$ male and $2 \%$ female) complained about muscle stiffness. None of the female patient complained either loss of flexibility or loss of tenderness while a percentage of male i.e. $3 \%$ complained both. No male was having fracture but only $2 \%$ of females were having hip fracture as per Figure 1 . 
Table 2. Comparison with local manufacturers with international manufacturers.

\begin{tabular}{cccc}
\hline International Users & Local Users & P value \\
\hline $3 \%$ & $19 \%$ & $* 0.001$ \\
\hline
\end{tabular}

Table 3. Patients symptoms with local and international brand user.

\begin{tabular}{|c|c|c|c|c|}
\hline & & Total & Male & Female \\
\hline \multirow{9}{*}{$\begin{array}{l}\text { Problems associated } \\
\text { with local manufacturers }\end{array}$} & Fatigue & $14(17.5 \%)$ & $6(16.7 \%)$ & $8(18.2 \%)$ \\
\hline & Hair loss & 7 (8.8\%) & $1(2.8 \%)$ & $6(13.6 \%)$ \\
\hline & Depression & $16(20 \%)$ & $5(13.9 \%)$ & $11(25 \%)$ \\
\hline & Infertility & $6(7.5 \%)$ & $3(8.3 \%)$ & $3(6.8 \%)$ \\
\hline & Recurrent abortion & $4(5 \%)$ & $1(2.8 \%)$ & $3(6.8 \%)$ \\
\hline & Libido & $9(11.3 \%)$ & $6(16.7 \%)$ & $3(6.8 \%)$ \\
\hline & Cold or hot intolerance & $3(3.8 \%)$ & $1(2.8 \%)$ & $2(4.5 \%)$ \\
\hline & Weight gain & $9(11.3 \%)$ & 7 (19.4\%) & $2(4.5 \%)$ \\
\hline & Swelling in lower extremities & $12(15 \%)$ & $6(16.7 \%)$ & $6(13.6 \%)$ \\
\hline \multirow{18}{*}{$\begin{array}{l}\text { Symptoms related to } \\
\text { Hypothyroidism }\end{array}$} & Hip fractures & $1(1.3 \%)$ & $0(0 \%)$ & $1(2.3 \%)$ \\
\hline & Bone fractures & $7(8.8 \%)$ & $3(8.3 \%)$ & $4(9.1 \%)$ \\
\hline & Cramps muscle ache and bone pain & $52(65 \%)$ & $24(66.7 \%)$ & $28(63.6 \%)$ \\
\hline & Weak and brittle finger nails & $10(12.5 \%)$ & $3(8.3 \%)$ & $7(15.9 \%)$ \\
\hline & Low over all fitness & $30(37.5 \%)$ & $11(30.6 \%)$ & $19(43.2 \%)$ \\
\hline & Anxiety and depression & $48(60 \%)$ & $20(55.6 \%)$ & $28(63.6 \%)$ \\
\hline & Behavioral changes and mood swings & $32(40 \%)$ & $12(33.3 \%)$ & $20(45.5 \%)$ \\
\hline & Edema in lower extremities & $38(47.5 \%)$ & $17(47.2 \%)$ & $21(47.7 \%)$ \\
\hline & Back pain & $14(17.5 \%)$ & $7(19.4 \%)$ & $7(15.9 \%)$ \\
\hline & Weakness and fatigue & $43(53.8 \%)$ & $19(52.8 \%)$ & $24(54.5 \%)$ \\
\hline & Stiffness & $4(5 \%)$ & $3(8.3 \%)$ & $1(2.3 \%)$ \\
\hline & Loss of tenderness & $1(1.3 \%)$ & $1(2.8 \%)$ & $0(0 \%)$ \\
\hline & loss of flexibility & $1(1.3 \%)$ & $1(2.8 \%)$ & $0(0 \%)$ \\
\hline & Grating sensation & $13(16.3 \%)$ & 7 (19.4\%) & $6(13.6 \%)$ \\
\hline & Cracking and creaking & $26(32.5 \%)$ & $14(38.9 \%)$ & $12(27.3 \%)$ \\
\hline & Disturbance in menstruation cycle & $19(23.8 \%)$ & $7(19.4 \%)$ & $12(27.3 \%)$ \\
\hline & Vertigo & $16(20 \%)$ & $7(19.4 \%)$ & $9(20.5 \%)$ \\
\hline & Associated heart diseases & $11(13.8 \%)$ & $5(13.9 \%)$ & $6(13.6 \%)$ \\
\hline
\end{tabular}

\section{Awareness, Empowerment, Quality and Patient Centricity}

Only $2 \%$ of the patients were having awareness about the disease burden as per Table 4 (2.5\%). Patient having age of 25 years were more aware as compared to the middle or old aged patient. Before counseling about the diseases burden it was $3 \%$ and after it found to be $15 \%(P=0.001)$ as per Table 5 .

Before counseling and discussion all the subjects had a thought that they always depended upon their doctor and would depend on their doctors/physician for their whole life (92.5\%) and after discussion/counseling, the dependency shown was $67.5 \%$ as per Table 4 . The level of significance before and after was found to be 0.007 as per Table 5 .

Patient empowerment were a very new concept for them and only $2.5 \%$ of the subjects knew before counseling and after it was found to be $26.3 \%$ as per Table 4 . The intent was to give them the realization that you are the only custodian of yourself. The level of empowerment before and after were found to be (0.004) as per Table 5 (Figure 2).

Knowledge related to the Patient centric health care before were $1.3 \%$ and after discussion the level of the understanding about the concept were $16.3 \%$ as shown in Table 4 . Before and after the understanding of the patients were found to (0.022) as per Table 5. 


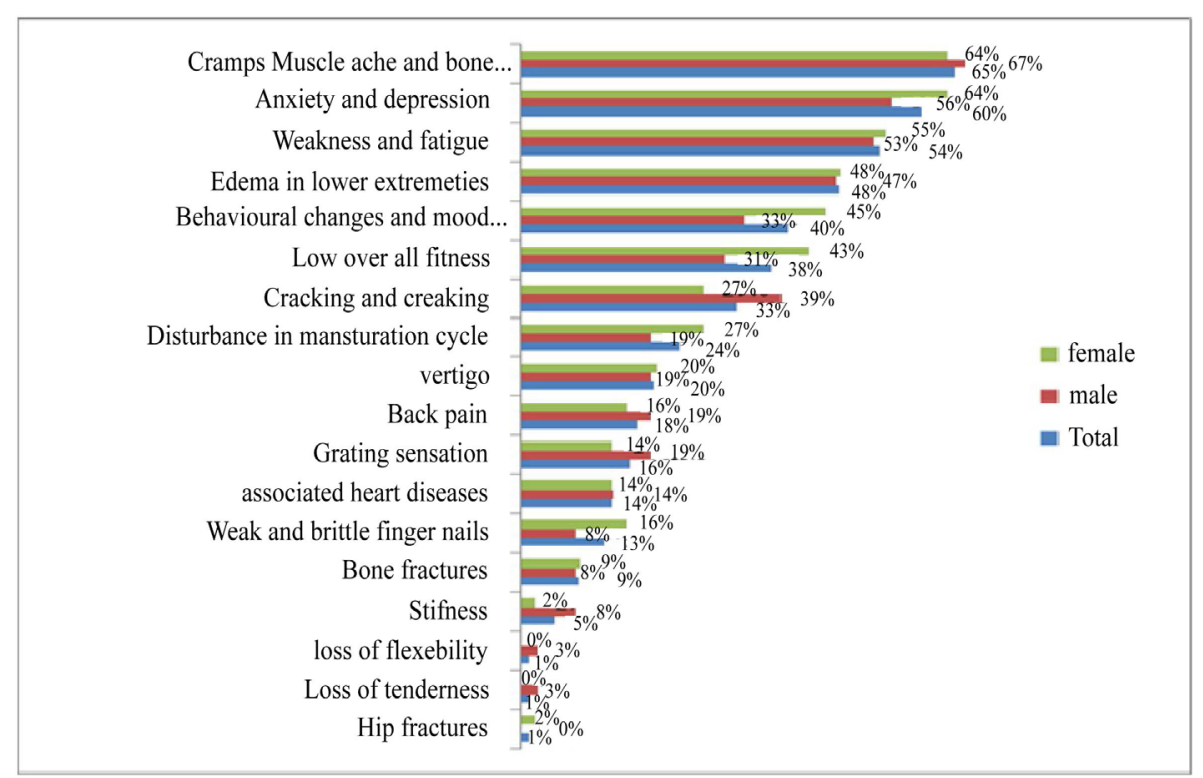

Figure 1. Relationship of male and female patients with different associate complains.

Table 4. Parameters for patient centricity, quality health care and empowerment.

\begin{tabular}{|c|c|c|c|}
\hline & & Count & Column N \% \\
\hline \multirow{3}{*}{ Before-Do you have awareness about the diseases burden? } & No idea & 0 & $0.0 \%$ \\
\hline & Yes & 2 & $2.5 \%$ \\
\hline & No & 78 & $97.5 \%$ \\
\hline \multirow{3}{*}{ After-Do you have awareness about the diseases burden? } & No idea & 0 & $0.0 \%$ \\
\hline & Yes & 15 & $18.8 \%$ \\
\hline & No & 65 & $81.3 \%$ \\
\hline \multirow{2}{*}{ Before-Are you always depend upon your doctor for your disease? } & Yes & 74 & $92.5 \%$ \\
\hline & No & 6 & $7.5 \%$ \\
\hline \multirow{2}{*}{ After-Are you always depend upon your doctor for your disease? } & Yes & 54 & $67.5 \%$ \\
\hline & No & 26 & $32.5 \%$ \\
\hline \multirow{2}{*}{ Before-empowerment } & Yes & 2 & $2.5 \%$ \\
\hline & No & 78 & $97.5 \%$ \\
\hline \multirow{2}{*}{ After-empowerment } & Yes & 21 & $26.3 \%$ \\
\hline & No & 59 & $73.8 \%$ \\
\hline \multirow{2}{*}{ Before-Do you Know about patient centric health care? } & Yes & 1 & $1.3 \%$ \\
\hline & No & 79 & $98.8 \%$ \\
\hline \multirow{2}{*}{ After-Do you Know about patient centric health care? } & Yes & 13 & $16.3 \%$ \\
\hline & No & 67 & $83.8 \%$ \\
\hline \multirow{2}{*}{ Before-Do you know about quality health care system? } & Yes & 1 & $1.3 \%$ \\
\hline & No & 79 & $98.8 \%$ \\
\hline \multirow{2}{*}{ After-Do you know about quality health care system? } & Yes & 13 & $16.3 \%$ \\
\hline & No & 67 & $83.8 \%$ \\
\hline
\end{tabular}

Patients' level of the quality health care system before discussion was found to be $1.3 \%$ as shown in Table 4. The level of significance before and after about the quality health care system was found to be significant $(\mathrm{P}=0.020)$ as shown in Table 5. 


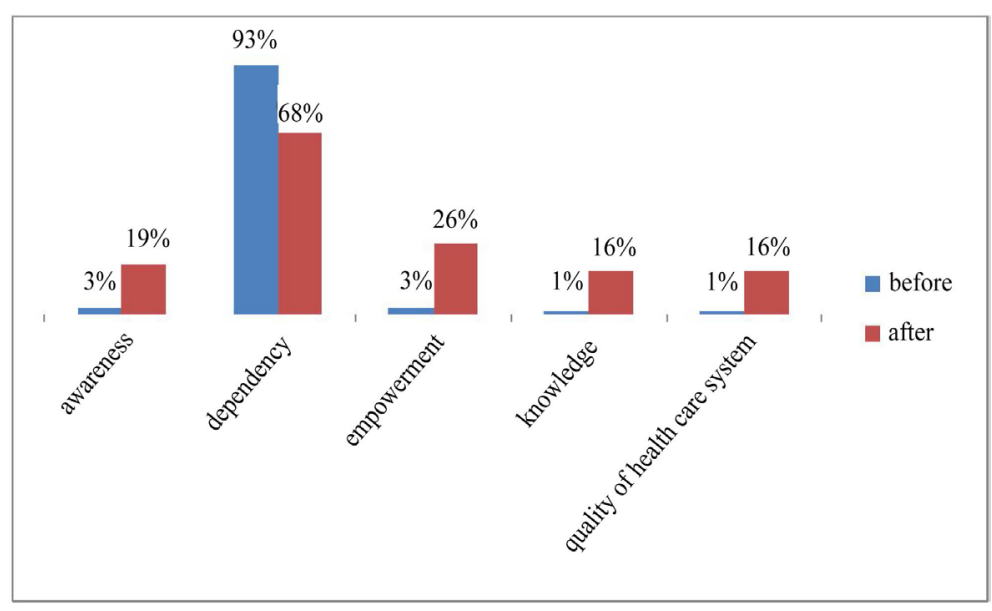

Figure 2. Parametric analysis related to patient centricity, quality health care and empowerment.

Table 5. Parametric analysis related to patient centricity, quality health care and empowerment.

\begin{tabular}{ccccc}
\hline Parameters & Before & After & P value \\
\hline Awareness & $3 \%$ & $19 \%$ & $0.001^{*}$ \\
Dependency & $93 \%$ & $68 \%$ & 0.007 \\
Empowerment & $3 \%$ & $26 \%$ & $0.004^{*}$ \\
Knowledge & $1 \%$ & $16 \%$ & $0.022^{*}$ \\
Quality of health care system & $1 \%$ & $16 \%$ & $0.020^{*}$ \\
\hline
\end{tabular}

\section{Recommendation}

Developing countries try to survive with multiple healthy related issues. Concept building related to patient empowerment and patient centricity can improve the health care ecosystem, especially the disease which patient carry for whole life like hypothyroidism. Quality health care is the right of every individual, but before that we should analyze the readiness of patient centricity in health care providers via different organizations. After evaluation there should be proper improvement guidelines for the HCPs with empowerment concept.

\section{Conflict of Interest}

The authors have no conflict of interest.

\section{References}

[1] Carle, A., Laurberg, P., Pedersen, I.B., Knudsen, N., Perrild, H., Ovesen, L., et al. (2006) Epidemiology of Subtypes of Hypothyroidism in Denmark. European Journal of Endocrinology, 154, 21-28. http://dx.doi.org/10.1530/eje.1.02068

[2] Brix, T.H., Kyvik, K.O. and Hegedüs, L. (2000) A Population-Based Study of Chronic Autoimmune Hypothyroidism in Danish Twins. The Journal of Clinical Endocrinology Metabolism, 85, 536-539.

[3] Brix, T.H., Hansen, P.S., Kyvik, K.O. and Hegedüs, L. (2000) Cigarette Smoking and Risk of Clinically Overt Thyroid Disease: A Population-Based Twin Case-Control Study. Archives of Internal Medicine, 160, 661-666. http://dx.doi.org/10.1001/archinte.160.5.661

[4] Klein, I. and Ojamaa, K. (2001) Thyroid Hormone and the Cardiovascular System. The New England Journal of Medicine, 344, 501-509.http://dx.doi.org/10.1056/NEJM200102153440707

[5] Kahaly, G.J. and Dillmann, W.H. (2005) Thyroid Hormone Action in the Heart. Endocrine Reviews, 26, 704-728. http://dx.doi.org/10.1210/er.2003-0033

[6] Kahaly, G.J. (2000) Cardiovascular and Atherogenic Aspects of Subclinical Hypothyroidism. Thyroid, 10, 665-679. http://dx.doi.org/10.1089/10507250050137743

[7] Biondi, B. and Cooper, D.S. (2012) Subclinical Thyroid Disease. The Lancet, 379, 1142-1154. http://dx.doi.org/10.1016/S0140-6736(11)60276-6 
[8] Milla, C.E. and Zirbes, J. (2012) Pulmonary Complications of Endocrine and Metabolic Disorders. Paediatric Respiratory Reviews, 13, 23-28. http://dx.doi.org/10.1016/j.prrv.2011.01.004

[9] Díez, J.J., Sánchez, P. and Iglesias, P. (2011) Prevalence of Thyroid Dysfunction in Patients with Type 2 Diabetes. Experimental and Clinical Endocrinology and Diabetes, 199, 201-207. http://dx.doi.org/10.1055/s-0031-1271691

[10] Perros, P., McCrimmon, R.J., Shaw, G. and Frier, B.M. (1995) Frequency of Thyroid Dysfunction in Diabetic Patients: Value of Annual Screening. Diabetic Medicine, 12, 622-627.

[11] Jenkins, R.C. and Weetman, A.P. (2002) Disease Associations with Autoimmune Thyroid Disease. Thyroid, 12, 977-988. http://dx.doi.org/10.1089/105072502320908312

[12] Rastogi, M.V. and LaFranchi, S.H. (2010) Congenital Hypothyroidism. Orphanet Journal of Rare Diseases, 5, 17. http://dx.doi.org/10.1186/1750-1172-5-17

[13] Kalra, S. and Kalra, B. (2006) Answering the Urgent Need for Diabetes Care Professionals in Northern India. Diabetes Voice, 51, 11-13.

[14] Kalra, S., Kalra, B. and Kumar, N. (2007) Prevention and Management of Diabetes: The Role of the Physiotherapist. Diabetes Voice, 52, 12-15.

[15] Agrawal, N., Kalra, S., Kalra, B. and Agrawal, S. (2010) Telephonic Patient Support: The Didi (Elder Sister) Project. Pediatric Diabetes, 11, S65.

[16] Skovlund, S.E., Peyrot, M., and the DAWN International Advisory Panel (2005) The Diabetes Attitudes, Wishes, and Needs (DAWN) Program: A New Approach to Improving Outcomes of Diabetes Care. Diabetes Spectrum, 18, $136-142$. http://dx.doi.org/10.2337/diaspect.18.3.136 
Scientific Research Publishing (SCIRP) is one of the largest Open Access journal publishers. It is currently publishing more than 200 open access, online, peer-reviewed journals covering a wide range of academic disciplines. SCIRP serves the worldwide academic communities and contributes to the progress and application of science with its publication.

Other selected journals from SCIRP are listed as below. Submit your manuscript to us via either submit@scirp.org or Online Submission Portal.
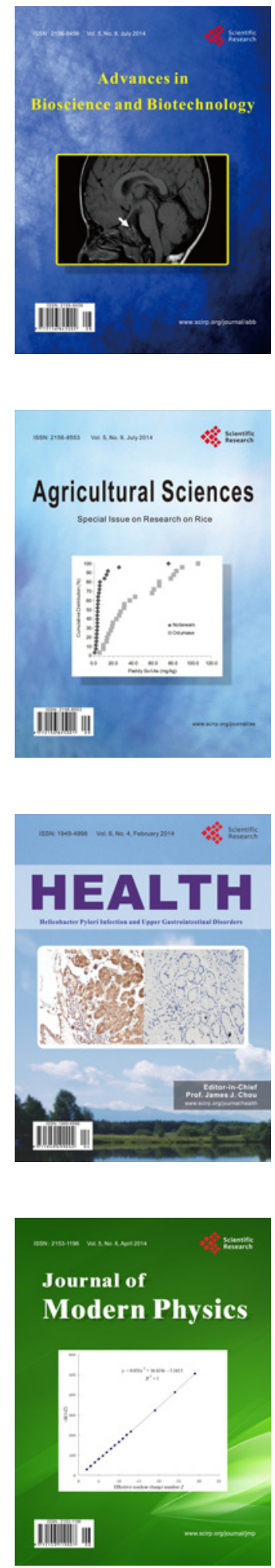
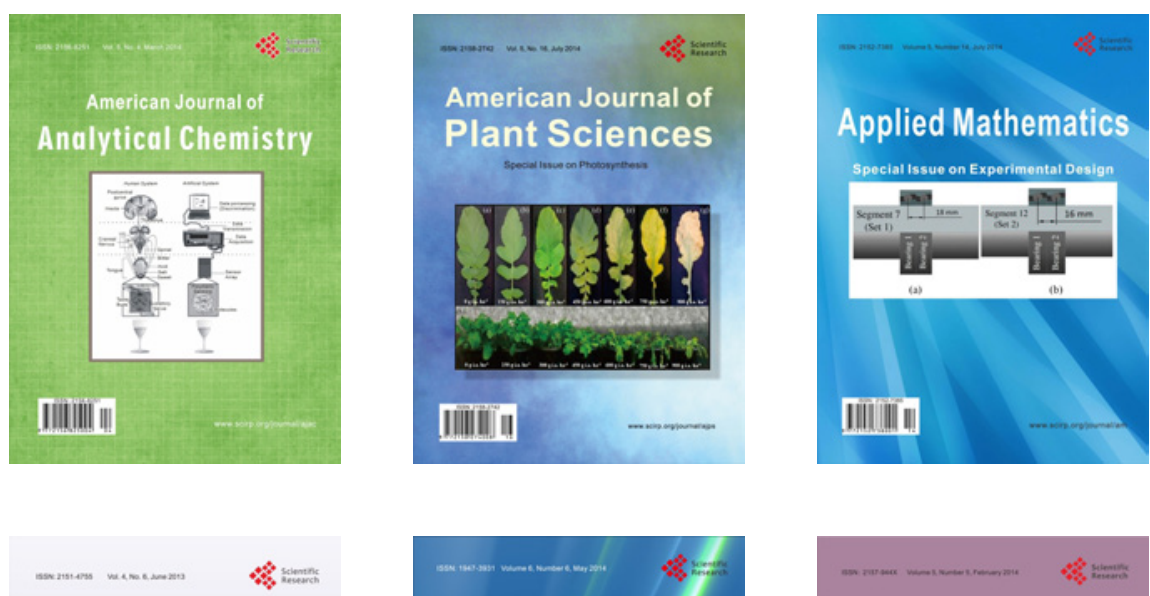

Creative Education
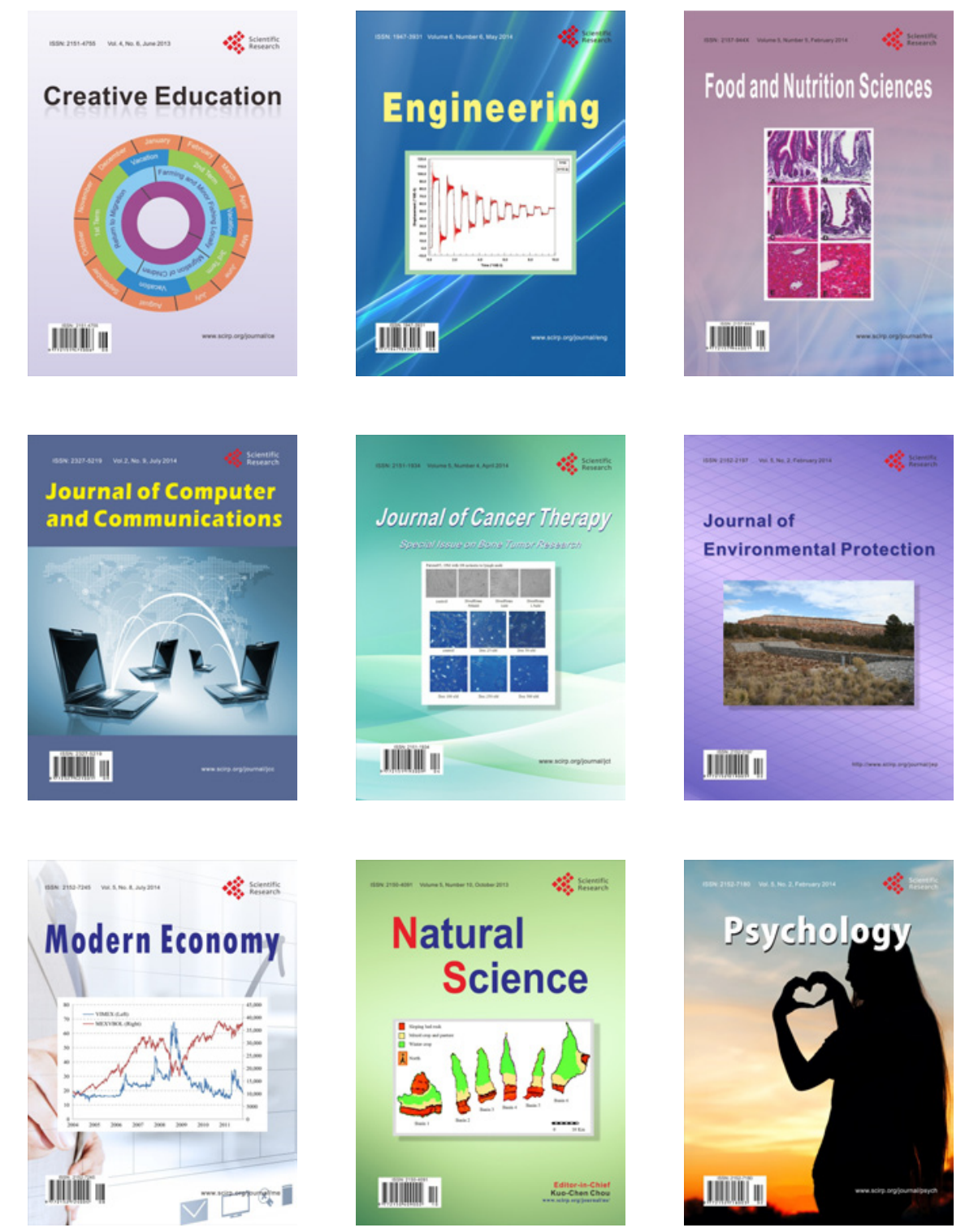